\title{
РАЗРАБОТКА ПРОАКТИВНОЙ СИСТЕМЫ УПРАВЛЕНИЯ ВОССТАНОВЛЕНИЕМ И РЕНОВАЦИЕЙ ОБОРУДОВАНИЯ НА НЕФТЕДОБЫВАЮЩИХ ПРЕДПРИЯТИЯХ
}

\author{
(C) 2021 Томазова Олеся Владимировна \\ кандидат экономических наук, доцент \\ Самарский государственный технический университет, Россия, Самара \\ E-mail: ovtom@mail.ru
}

В статье раскрыты проблемы управления поддержания в работоспособном состоянии средств труда нефтедобывающих предприятий. Рассмотрены существующие модели управления процессами восстановления и реновации оборудования. Сформирована методология проактивной системы управления средствами труда на нефтедобывающих предприятиях.

Ключевые слова: система управления, проактивность, нефтедобывающие предприятия, восстановление и реновация оборудования, система планово-предупредительных ремонтов.

\section{Введение}

На нефтедобывающих предприятиях постоянно совершенствуется процесс производства, а именно, используются новые технологии добычи и воздействия на пласт, решаются экологические вопросы при добыче нефти и ее подготовке, рассматривается повышение квалификации персонала и цифровизация основных процессов производства. Все вышеперечисленное предполагает в процессе реализации поставленных задач, современное и высокотехнологичное оборудование, требующее своевременное и качественное обслуживание.

Наряду с вопросами поддержания работоспособности средств труда стоит вопрос о способах осуществления процессов восстановления и реновации. На сегодняшний день, в практике нефтедобывающих предприятий принято значительную часть работ передавать на сторону сервисным организациям на тендерной основе. Все работы связанные с восстановлением и реновацией оборудования выполняются высококвалифицированными работниками, специализированным оборудованием. На исследуемых предприятиях используется система плановопредупредительных ремонтов (ППР), которая является частью существующей системы управления вспомогательного производства. Согласно проведенным исследованиям по выбранной теме, автору видится, что в современных условиях хозяйствования требуется совершенствование системы управления восстановления и реновации оборудования.

Ниже рассмотрены модели управления про- цессами восстановления (рис. 1) и реновации (рис. 2) оборудования, которые являются составляющими действующей системы управления поддержания работоспособности средств труда.

На рисунке 1 представлен процесс восстановления средств труда, который состоит из подпроцессов, служащих ориентирами для высшего менеджмента нефтедобывающих предприятий при принятии управленческого решения.

Описываемая модель восстановления оборудования включает в себя следующие подпроцессы:

- эксплуатация оборудования;

- система планово-предупредительного ремонта;

- диагностика оборудования;

- модернизация оборудования.

Для качественной реализации перечисленных подпроцессов требуется специализированное оборудование, квалифицированный персонал, запасные части и материалы, поэтому большая часть из выше перечисленного отдается на выполнение сервисным организациям. Также в исследуемой модели есть подпроцессы «диагностика», «система плановопредупредительных ремонтов», которая содержит в себе элементы проактивности. Они реализуются через предупредительные виды работ, которые выполняются строго в определённый период времени и по данным, собранным за предыдущие периоды, и мониторингу. Это способствует оптимизации расходов на выполнение работ по восстановлению оборудования и возможность спланировать дальнейшие расходы в будущем. 


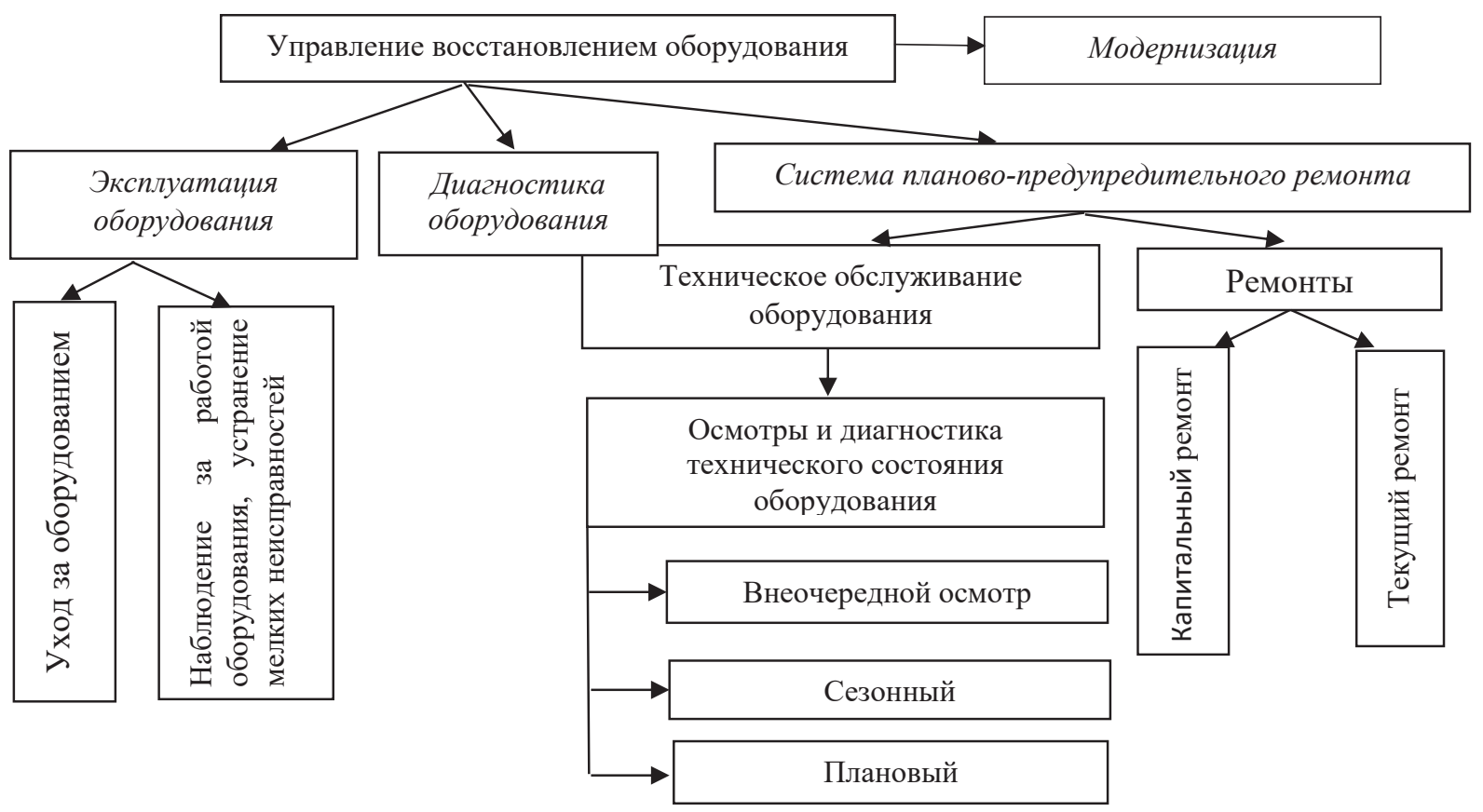

Рис. 1. Модель управления восстановлением оборудования нефтедобывающих предприятий.

При использовании действующей модели управления процессом реновации оборудования, менеджмент нефтедобывающих предприятий может своевременно выявить причину неэффективной эксплуатации оборудования и оперативно осуществить замену. Описываемая модель представлена на рисунке 2.

Однако, все вышеприведенное базируется на той же единой системе плановопредупредительных ремонтов, которая учитывает не все особенности эксплуатации оборудования нефтедобывающих предприятий.

Однако, все вышеприведенное базируется на той же единой системе плановопредупредительных ремонтов, которая учитывает не все особенности эксплуатации оборудования нефтедобывающих предприятий.

Поскольку при анализе литературных источников автором не было определено единого подхода в вопросах восстановления и реновации оборудования нефтедобывающих предприятий, то в данной научной статье предлагается методология формирования проактивной си- стемы управления.

Данной проблеме посвящены теоретические исследования отечественных ученых, которые по-разному выстраивают дефиницию понятия «проективное управление». Крылов А.В.* под проактивным управлением понимает сложные сетевую и иерархическую структуры, оперативно реагирующие на ранних стадиях их развития на сложные вызовы внешней среды на основании разработанных сценариев их оптимального функционирования. Абубакирова И. О.** под проактивным управлением подразумевает способность функционирующего хозяйственного субъекта выявлять изменения факторов внешней среды так, чтобы предотвратить их негативное влияние на создание ценности для клиентов; по мнению Филимоновой Н. М., Башариной С. М., Никишиной Е.С.*** под проактивным управлением следует понимать целенаправленное дискретное воздействие менеджмента высшего звена на персонал, с целью формирования у него навыков и компетенций проактивной адаптации на основе данных изменения внешней сре-

* А.В.Крылов. Проактивное управление и его применение при управлении сложными организационнотехническими объектами/Вычислительные системы и программирование. С.220-224

** Ю.Д.Абубакирова. Проактивное управление-современный подход к управлению организацией. 2017 г. С. 356-358.

**** Н. М. Филимонова, С. М. Башарина, Е. С. Никишина. Проектное управление инвестиционно-инновационными проектами как механизм повышения конкурентоспособности региона/Экономика и управление. 2009 г. № 4 . C.49-54. 


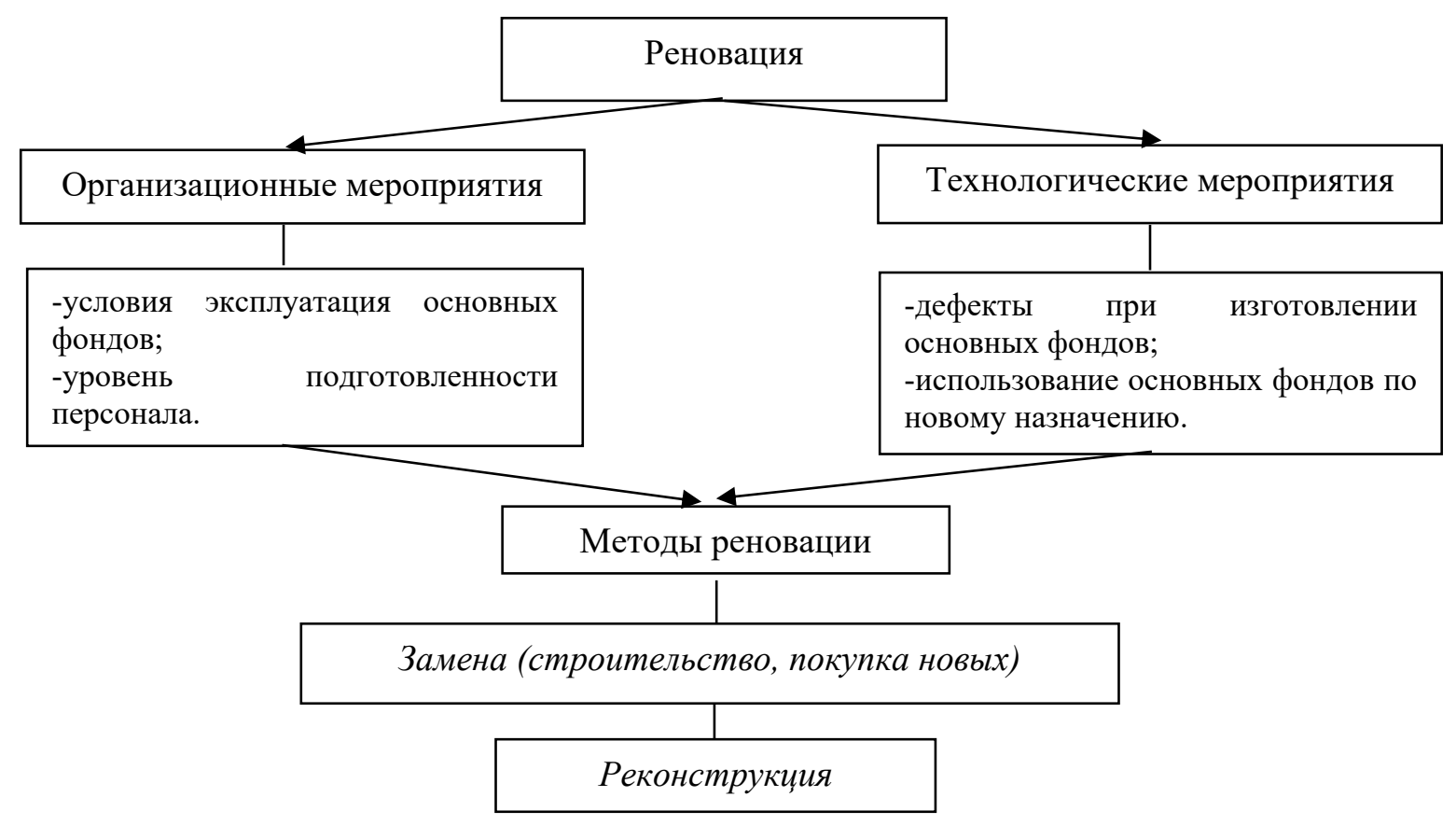

Puc. 2. Схема модели управления реновацией оборудования нефтедобывающих предприятий

ды, полученных путем ее мониторинга; Бушуева Н.С." считает, что философия проактивного управления базируется на запланированном результате деятельности относительно контрольных точек реализации проекта; Ньюстром Д.В., Дэвис К.** считают, что проактивность - это предвидение событий и перемен, с целью оптимального, устойчивого функционирования организации; Гайнутдинов Р. М.**** считает, что проактивность начинается с паузы, когда индивид планирует цели и тактику их достижения, начиная с осмысления своей первоначальной парадигмы; Сурженко А.В ${ }^{* * * * * *}$ основным принципом проактивного управления продажами считает предвидение возможного действия негативных факторов внешней среды.

Вышеизложенные теоретические положения позволили автору сформулировать следующее понятие: «Проактивная система управления восстановлением и реновацией оборудования нефтедобывающих предприятий» это свод правил и принципов построения системы, обеспечивающей принятие управленческих решений, направленных на формулирование обоснованной реальной цели восстановления или реновации оборудования для добычи и подготовки углеводородов, формулирования рисков его возможной прерывной работы и устаревания и разработки предупреждающих действий, обеспечивающих заблаговременную коррекцию процессов его восстановления или реновации.

Исследования, проведенные автором на предприятиях нефтедобычи, позволили выполнить сравнительный анализ существующей и проактивной систем управления. Результаты анализа приведены в таблице 1.

Из таблицы 1 видно, что, сравнивая системы управления можно увидеть существенные различия. Наиболее существенным видится при формировании самих систем принцип предвидения и принятия текущей ситуации; принятие управленческих решений; используемые регламенты при реализации процесса восстановления. Но особенно важным различием является влияние факторов на работу и эксплуатацию оборудования. Не всегда только известные фак-

* Н.С.Бушуева Проактивное управление проектами организационного развития в условиях неопределённости/ “Управління проектами та розвиток виробництва”, 2007, № 2(22).

** Д. В.Ньюстром, К. Дэвис. Организационное поведение.-СПб.: Изд-во Питер-Юг, 2000. - 448 с.

*** Р.М.Гайнутдинов. Рефлексивно-проактивное управление как условие инновационного развития современной организации/ Центр научного сотрудничества «Интерактив плюс».

**** А.В.Сурженко. Проактивное управление продажами промышленного предприятия/Вестник Белгородского университета кооперации, экономики и права. 2015 г. № 3. С. 388-389. 
Таблица 1. Сравнение систем управления восстановлением и реновацией оборудования.

\begin{tabular}{|l|l|}
\hline $\begin{array}{l}\text { Существующая система восстановления и рено- } \\
\text { вации оборудованиия }\end{array}$ & $\begin{array}{l}\text { Проактивная система восстановления и ренова- } \\
\text { ции оборудования }\end{array}$ \\
\hline $\begin{array}{l}\text { Формирование системы восстановления и реновации } \\
\text { оборудованиия основано на принципе реактивности } \\
\text { - «следование по течению» }\end{array}$ & $\begin{array}{l}\text { Формирование системы восстановления и реновации } \\
\text { оборудованиия основано на принципе проактивно- } \\
\text { сти - педвидение» }\end{array}$ \\
\hline $\begin{array}{l}\text { Нормативно-плановая система управления восста- } \\
\text { новлением и реновацией оборудования }\end{array}$ & $\begin{array}{l}\text { Дифференцировано-целевая система управления } \\
\text { восстановлением и реновацией оборудования }\end{array}$ \\
\hline $\begin{array}{l}\text { Управленческие решения ориентированы на теку- } \\
\text { щую ситуацию }\end{array}$ & $\begin{array}{l}\text { Управленческие решения ориентированы на страте- } \\
\text { гическую перспективу }\end{array}$ \\
\hline $\begin{array}{l}\text { Регламент восстановления оборудования, стабильно } \\
\text { действующий в течении амортизационного периода } \\
\text { объекта основных средств }\end{array}$ & $\begin{array}{l}\text { Регламент восстановления оборудования, преры- } \\
\text { вающийся в случае выявления нецелесообразности } \\
\text { восстановления объекта основных средств }\end{array}$ \\
\hline $\begin{array}{l}\text { Учет и применение условий эксплуатации, оговорен- } \\
\text { ных в паспорте объекта основных средств, ко всей } \\
\text { совокупности однотипного оборудования }\end{array}$ & $\begin{array}{l}\text { Учет влияния максимального числа факторов, ока- } \\
\text { зывающих существенное влияние на работу данной } \\
\text { единицы объекта основных средств }\end{array}$ \\
\hline
\end{tabular}

торы, такие как природно-климатические условия эксплуатации и горно-геологические условия, являются основополагающими. Автором предложена еще одна группа факторов, которые оказывают влияние на работу средств труда это осложняющие факторы. Они оказывают влияние на подземную группу оборудования и существенно сокращают их период эксплуатации.

При формировании проактивной системы управления, высшему менеджменту, при принятии управленческого решения, предстоит взглянуть на ситуацию комплексно, а не фрагментарHO.

Предложенная автором методология формирования проактивной системы управления восстановлением и реновацией оборудования основана на методологических принципах, инструментарии проактивного управления, ориентированных на успешную и своевременную реализацию функций управления по поддержанию в работоспособном состоянии средств труда.

Схема методологии представлена на рис. 3.

В разработанной авторской методологии проактивной системы управления восстановлением и реновацией оборудования нефтедобывающих предприятий достижима становится поставленная цель, через взаимодействие внутри предприятия, на основе методологических компонентов и составляющих проактивной системы управления*.

Проактивная система управления восстановлением и реновацией оборудования также позволит нефтедобывающим предприятиям:
- систематизировать информацию об имеющихся единицах средств труда, инструментах, запасных частях и принадлежностях и хранить эту информацию в электронном виде;

- хранить информацию об аналогичных моделях оборудования и учитывать опыт их восстановления и реновации, то есть заблаговременно проводить ремонты и обслуживание, учитывая осложняющие факторы и горно-геологические условия их эксплуатации;

- оперативно планировать профилактические и ремонтные работы, контролировать ход исполнения этих работ;

- снизить число аварий и простоев из-за отказов оборудования;

- снизить эксплуатационные затраты и потери путём исключения неэффективных видов внеплановых и планово-предупредительных ремонтов.

Проактивность в исследуемой системе управления проявляется в комплексном подходе к процессам восстановления и реновации оборудования. Комплексность заключается в том, что автором предложено рассматривать сохранения работоспособности средств труда опираясь не только на систему ППР, но и на профилактический комплекс мероприятий, корректирующий и прогнозируемые мероприятия. А также, особое внимание уделяется отраслевой специфике, в которой эксплуатируется оборудование. Это природно-климатические условия, осложняющие факторы, горно-геологические условия.

\footnotetext{
* Томазова О.В. Методология формирования проактивной системы управления восстановлением и реновацией оборудования предприятий нефтегазового комплекса РФ/Экономика и предпринимательство. 2014. - 11-4 (52). С. 632-634.
} 


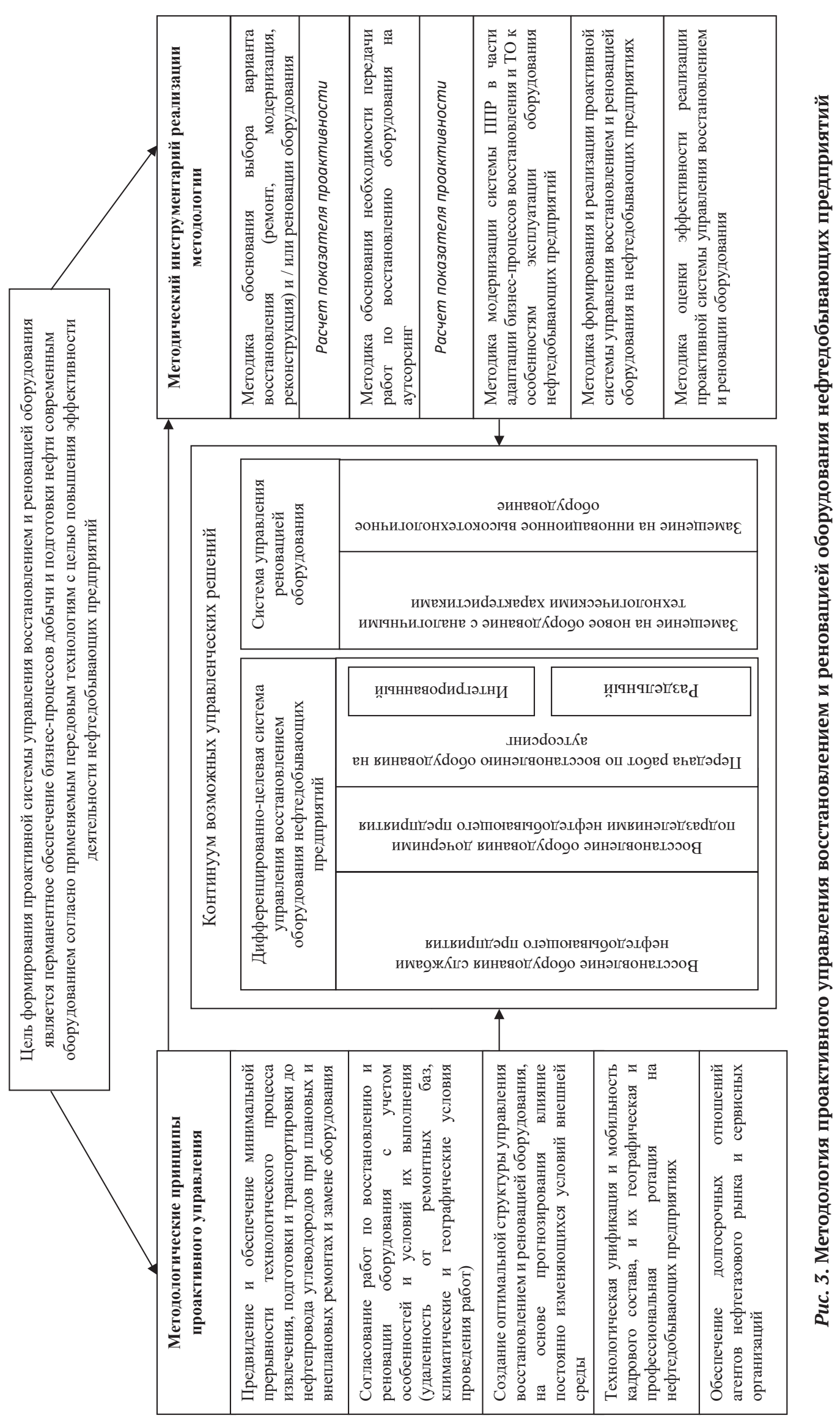




\section{Библиографический список}

1. А.В. Крылов Проактивное управление и его применение при управлении сложными организационнотехническими объектами/Вычислительные системы и программирование. С.220-224

2. Ю.Д. Абубакирова Проактивное управление-современный подход к управлению организацией. 2017 г. С. 356-358.

3. Н.М. Филимонова, С. М.Башарина, Е. С. Никишина Проектное управление инвестиционно-инновационными проектами как механизм повышения конкурентоспособности региона/Экономика и управление. 2009 г. № 4. С.49-54.

4. Н.С. Бушуева Проактивное управление проектами организационного развития в условиях неопределённости/ “Управління проектами та розвиток виробництва”, 2007, № 2(22).

5. Д.В. Ньюстром, К. Дэвис Организационное поведение.- СПб.: Изд-во Питер-Юг, 2000. - 448 с.

6. Р.М. Гайнутдинов Рефлексивно-проактивное управление как условие инновационного развития современной организации/ Центр научного сотрудничества «Интерактив плюс».

7. А.В. Сурженко Проактивное управление продажами промышленного предприятия/Вестник Белгородского университета кооперации, экономики и права. 2015 г. № 3. С. 388-389.

8. Томазова О.В. Методология формирования проактивной системы управления восстановлением и реновацией оборудования предприятий нефтегазового комплекса РФ/Экономика и предпринимательство. 2014. 11-4 (52). С. 632-634. 